\title{
Requirements of Electronic Management in the Management of Kindergarten Institutions
}

\author{
Fathy Abd-Elrasol Mohamed, Rshad abo Elmagd Mostafa and Ebtsam Mohamed Abd Ellah \\ Faculty of Education, South Valley University
}

\begin{abstract}
The study aimed to identify the requirements of the electronic in the management of kindergarten management in kindergartens in terms of its concept, objectives, importance, and requirements of development. The study addressed a set of requirements which are represented in the administrative, human, technical, and financial and security requirements. And the human community witnesses a group of transformations and changes which became a fundamental feature of it. Some of these features are represented in the multiplicity of sources of knowledge such as the wealth of information and sharing of technology and entrepreneurship of space. These changes and transformations have great implications on educational institutions particularly kindergartens including what it undertake of responsibilities and tasks towards the progress and raise of Nations. And the emergence of many new trends in management, including electronic management, serves as a modern entrance in management and as a result of these challenges it must resort to the use of technological innovations in all fields. And the success of the electronic management project requires providing a set of requirements for it and the use of kindergartens for modern technological means.
\end{abstract}

Keywords: Electronic Management; Kindergarten Institutions

Citation: Mohamed., Requirements of Electronic Management in the Management of Kindergarten Institutions. SVU-Journal of abstract 2019, Vol.1: pp1 (retrieved from the Journal of Educational Sciences; 2018, No.34; pp 14).

Copyright: Publisher South Valley University. This is an open access article distributed under the terms of the creative common attribution license, which permits unrestricted use, distribution and reproduction in any medium provided the original author and source are created. 